\section{THU0206 CLINICAL SIGNIFICANCE OF QTC DISPERSION AND EJECTION FRACTION OF THE LEFT VENTRICLE IN PATIENTS WITH RHEUMATOID ARTHRITIS}

BV Obradovic-Tomasevic, L Radunovic, K Cobeljic, V Obradovic. Rheumatology-Cardiology, Clinical Hospital Zemun, University Medical School, Belgrade, Belgrade, Yugoslavia

\subsection{6/annrheumdis-2001.1108}

Background QTc dispersion (QTc-d) is an indicator of imbalanced ventricular activity and represents a useful prediction for the appearance of ventricular arrhythmias. The longer QTc-d is more frequent in the patients with the duration of rheumatoid arthritis (RA). Echocardiographically estimated systolic function by ejaction fraction (EF\%) has a clinical and therapeutical significance.

Objectives The objective of the research was to examine two groups of patients with RA as regards the duration of the disease to 5 and 10 years.

It was necessary to establish in which group ventricular arrhythmias were more frequent in relation to QTc-d and in relation to $\mathrm{EF} \%$ as well.

Methods 50 patients were examined, 30 females and 20 females, whose average age of $58 \pm 3$. All the patients were divided into two groups. The first group included 28 patients with the duration of the diseases to 5 years, and the second group consisted of 22 patients with the duration of the disease from 5 to 10 years. On 12-leed ECG Qtc-d was measured as a difference QTc max - Qtc min and it was corrected by Bazett's formula. All the measures were done in sinus rhythm. Echocardiographic estimation of the systolic function was determined from EF\%, 2-DEchocardiograpphy.

Results The values of QTc-d in the first group were $50.5 \pm 2.5$ msec, whereas $\mathrm{EF} \%$ was $48 \% \pm 3.5$.

In the second group QTc-d was $78.5 \mathrm{msec} \pm 3.2$ and EF\% was $39 \% \pm 2.5$.

The longer QTc-d and lower EF\% were noted in all examined patients. However, in the second group of the patients, these values were considerably changed, which indicates that the duration of the disease is important. In the second group the ventricular arrhythmias were more frequent and they are very important in prognosis and treatment of those patients.

Conclusion Exanimated showed that the longer QTc-d was considerably longer in the second group of the patients. EF\% was considerably lower in the second group. The longer QTc-d and low EF\% were in good correlation with the ventricular arrhythmias.

\section{REFERENCES}

1 Goldeli O, Dursun E, Komsuoglu B. Dispersion of ventricular repolarization: a new marker of ventricular arrhythmias in patients with rheumatoid arthritis. J Rheunatol. 1998;25(3):447-50

2 Crawford M, DiMarco J, et al. Cardiology. Mosby, 2001; section 8:5.1010

\section{THU0207 ASYMPTOMATIC AND SYMPTOMATIC MYOCARDIAL ISCHEMIA IN PATIENTS WITH RHEUMATOID ARTHRITIS}

BV Obradovic-Tomasevic, L Radunovic, K Cobeljic, V Cvorovic, V Obradovic. RheumatologyCardiology, Clinical Hospital Zemun, University Medical School, Belgrade, Belgrade, Yugoslavia

\subsection{6/annrheumdis-2001.1109}

Background Holter electocardiography (Holter-ECG) is a useful uninvasive method with 24-hour-following of patients in hospital and especially out-of-hospital conditions. It was noticed that the ischaemic changes are noted on ECG and they can be without any subjective problems. Since the patients with rheumatoid arthritis have frequent chest pains, 24-hour-Holter ECG can indicate to whether those pains come from the heart.

Objectives The objective of the research was to place Holter ECG for $24 \mathrm{~h}$ to the out-patients with rheumatoid arthritis.

The objective was to follow ST-changes on Holter ECG with noting of the daily activities and subjective discomfort during those activities.

It was also important to examine the possible ischemias and the time of their appearance.

Methods 50 patients were examined, 30 females and 20 males, with the average age of $58 \pm 3$.

All the patients were after the medical check-up placed Holter ECG and given the paper for notes. It was advised that they should do all the activities and note all the difficulties $24 \mathrm{~h}$ a day. The analysis of Holter ECG and the notes were done separately by two different doctors.

Results Out of the 50 examined patients, 30 patients had 3 risk factors (hypertension, diabetes mellitus and hyperlipidaemia). 20 patients out of 50 examined had the risk factor - smoking. Episodes of symptomatic ischemia were noted in 20 patients and those were in the group which had all the three risk factors. Asymptomatic ischemia was noted in 15 patients and all of them had diabetes. Episodes of asyptomatic and symptomatic ischemia were noted in 15 patients. Asymptomatic and symptomatic ischemia occurred most frequently in the early morning hours, between 6 and 9 am, and 3 and 5 pm.

Conclusion The examination showed that the patients with rheumatoid arthritis had ST segment changes on Holter ECG. Episodes of symptomatic ischemia were more frequent, though special attention was paid to the episodes of asymptomatic ischemia as well, which most often appeared in early morning hours.

Episodes of asymptomatic ischemia were followed by complicated ventricular arrhythmias. Holter ECG is a useful method for following the patient with RA, because in this group the patients with the coronar diseases can be found. This is essential for the choice and dosage of a medicine.

\section{REFERENCES}

1 Crawford M, DiMarco J. Cardiology, Mosby 2001, section 2:9.1012

2 Tlustochowicz W, Piotrowicz R, Cwetsch A, et al. 24-h-ECG monitoring in patients with rheumatoid arthritis. Eur Heart J. 1995;16(6):848-51

\section{THU0208 EFFECTIVE AND SAFE LONG-TERM PREDNISONE THERAPY WITH STARTING DOSES OF 4 MG OR LESS IN 96 OF 102 CONSECUTIVE PATIENTS WITH RHEUMATOID ARTHRITIS}

T Pincus, T Sokka. Division of Rheumatology, Vanderbilt University, Nashville, USA

\subsection{6/annrheumdis-2001.1110}

Background Traditional approaches to corticosteroids in rheumatoid arthritis (RA) have been to avoid and/or discontinue their use if at all possible. However, corticosteroids are associated with improved patient well being, and are recognised to be disease modifying in RA.

Objectives To analyse results in use of long-term low-dose prednisone in 102 consecutive patients with RA seen in a weekly academic rheumatology clinic from 1982 to 1999, with a mean starting dose of $4.3 \mathrm{mg} /$ day, according to scores for functional capacity and pain on a multidimensional health assessment questionnaire (MDHAQ), and possible toxicities of corticosteroids. 